\title{
Patient Discomfort Associated with the Use of Intra-arterial lodinated Contrast Media: A Meta-Analysis of Comparative Randomized Controlled Trials
}

\author{
Peter A McCullough ${ }^{1 *}$ and Patrizio Capasso ${ }^{2}$
}

\begin{abstract}
Background: Discomfort characterized by pain and warmth are common adverse effects associated with the use of intra-arterial iodinated contrast media (CM). The objective of this review was to pool patient-reported outcomes available from head-to-head randomized controlled trials (RCTs) and to compare the discomfort rates associated with iso-osmolar contrast media (IOCM; i.e., iodixanol) to those reported with various low-osmolar contrast media (LOCM).

Methods: A review of the literature published between 1990 and 2009 available through Medline, Medline Preprints, Embase, Biological Abstracts, BioBase, Cab Abstracts, International Pharmaceutical Abstracts, Life Sciences Collection, Inside Conferences, Energy Database, Engineering Index and Technology Collection was performed to compare rates of discomfort associated with the use of the IOCM (iodixanol) vs. various LOCM agents in head-to-head RCTs. All trials with a Jadad score $\geq 2$ that reported patient discomfort data following intra-arterial administration of CM were reviewed, coded, and extracted.
\end{abstract}

Results: A total of 22 RCTs ( $n=8087$ ) were included. Overall discomfort (regardless of severity) was significantly different between patients receiving IOCM and various LOCMs (risk difference [RD] $-0.049 ; 95 \%$ confidence interval [Cl]: $-0.076,-0.021 ; p=0.001$ ). IOCM was favored over all LOCMs combined with a summary RD value of -0.188 ( $95 \% \mathrm{Cl}$ : $-0.265,-0.112 ; p<0.001)$ for incidence of pain, regardless of severity. A greater reduction in the magnitude of pain was observed with IOCM (iodixanol), particularly with selective limb and carotid/intracerebral procedures. Similarly, the meta-analysis of warmth sensation, regardless of severity, favored IOCM over LOCMs with an RD of -0.043 (95\% Cl: $-0.074,-0.011 ; p=0.008$ ). A positive linear relationship was observed between the discomfort effect size and age and a negative relationship with increasing proportion of women. The opposite trends were observed with warmth sensation.

Conclusions: IOCM was associated with less frequent and severe patient discomfort during intra-arterial administration. These data support differences in osmolality as a possible determinant of CM discomfort.

Keywords: contrast, discomfort, pain, intravascular, meta-analysis

\section{Background}

Iodinated contrast media $(\mathrm{CM})$ are essential to intravascular imaging procedures utilizing ionizing radiation. The development of CM has progressed from high-osmolar contrast media (HOCM) with osmolality (particle concentration in milliosmoles per kilogram of water) of $\sim 2000$

\footnotetext{
* Correspondence: peteramccullough@gmail.com

'St. John Providence Health System, Department of Medicine, Cardiology

Section, Providence Park Heart Institute, Novi, MI, USA

Full list of author information is available at the end of the article
}

$\mathrm{mOsm} / \mathrm{kg}$, to low-osmolar contrast media (LOCM) with a range of $\sim 600-800 \mathrm{mOsm} / \mathrm{kg}$, to iso-osmolal contrast media (IOCM) at $290 \mathrm{mOsm} / \mathrm{kg}$ that is isotonic to blood [1]. The intensity and frequency of adverse-effects associated with intravascular $\mathrm{CM}$ injections were reduced considerably with changes in usage from HOCM to LOCM. Nevertheless, patient discomfort during the intravascular administration remains a clinical challenge [2].

More than a third of patients in controlled clinical trials have been known to report CM-injection-related

\section{() Biomed Central}


discomfort, particularly local pain and an intense, unpleasant sensation of warmth [3]. The degree of discomfort and tolerability, generally considered to be directly proportional to the osmolality of CM, can influence the quality of the examination. Pain and discomfort may cause patients to move, thus resulting in motion artifacts and suboptimal images. Thus, it is of clinical value to further improve patient comfort and the diagnostic quality of radiological images [4].

Practice recommendations and guidelines issued by national societies have focussed on the risk of renal and cardiac complications after contrast and have not considered potential differences in pain and discomfort [5]. Likewise, most reviews and meta-analyses available in the literature have reported on contrast-induced acute kidney injury as the outcome of interest [1,6-9]. Patientreported subjective outcomes are infrequently reported in the radiology literature [10]. It is widely believed by radiologists that iso-osmolal contrast causes less discomfort that higher osmolar contrast media; there has not been definitive evidence to support this notion. Therefore, the goals of the current study were to pool data available from head-to-head randomized controlled trials (RCTs) and compare the frequency and severity of discomfort associated with IOCM (iodixanol) to those reported with various LOCM agents.

\section{Methods}

\section{Search Strategy}

A comprehensive search of the literature published from 1990 to Aug 2009 was performed by Nerac Inc. (Tolland, CT) using the following search string: (Visipaque*; iodixanol; 92339-11-2 $\backslash R N \backslash A L \backslash S U \backslash T M$ ) and (tolerab; tolerat"; "comfort; warmth; pain"; heat; warm $\backslash A L)$ and (double blind*; double-blind*; prospective; randomized; randomized; head <2> head; parallel $\backslash A L$ ) on August 27, 2009. The search was not limited to English language.

\section{Study Selection and Data Extraction}

The resources utilized along with total number of references located from each resource were: Medline (51); Medline Preprints (4); Embase (56); Biological Abstracts (8); BioBase (2); Cab Abstracts (1); International Pharmaceutical Abstracts (0); Life Sciences Collection (4); Inside Conferences (0); Energy Database (5); Engineering Index (1); and Technology Collection (0). Duplicate citations (57) were removed from the search results, and the remaining 75 abstracts were further reviewed for relevance.

A flow diagram illustrating the process of elimination used to select set of studies that met the inclusion/ exclusion criteria for the meta-analysis is presented in Figure 1. Studies that were not relevant to the topic of research, did not meet all the inclusion criteria, or were either review articles or meta-analyses were excluded. Additionally, studies using intravenous (IV) administration of CM were eliminated since the focus of the current study was limited to studies with intra-arterial (IA) administration of CM.

Data relating to more than 25 parameters were extracted from the RCTs, when available, into a standardized Microsoft ${ }^{\circledR}$ Excel (Redmond, WA) template and were assessed for quality and consistency by independent parties. The validated 5-point Jadad scale was used as an instrument for measuring the quality of each RCT with a score of 5 being indicative of excellent quality on a scale of 0 to 5 [11]. Only studies with a Jadad score of $\geq 2$ were included in the meta-analysis.

\section{Statistical Analyses}

Descriptive statistics were reported as means \pm standard deviations and counts with proportions as appropriate. Demographic summaries included gender, race, age, and weight for each study population, when available. Baseline characteristics were compared using the Student's ttest, Chi-square, or Wilcoxon rank sum test of the weighted averages, as appropriate.

The risk difference (RD) of pain, discomfort, warmth, and cold between IOCM (iodixanol) and the combined LOCM agents was determined. The first RD analysis was based on the incidence of an event, regardless of severity, while the second RD analysis evaluating severity was performed by grouping no events and mild events together and comparing this group to those with moderate and severe events. A subset analysis was performed between IOCM (iodixanol) and each LOCM agent. A meta-analysis was carried out by using the randomeffects model of DerSimonian and Laird to calculate pooled RDs and associated 95\% confidence intervals (CIs) for outcomes [12]. This method was chosen because it works independently of heterogeneity and coincides with the inverse variance fixed-effects model if there is no heterogeneity [12].

Statistical heterogeneity of trial results was tested using the Cochran $Q$ statistic and $I^{2}$, which indicate the percentage of the variability in effect estimates because of heterogeneity rather than chance. For the $Q$ statistic, $\mathrm{p}<0.10$ was considered significant. Subgroup analyses to assess the effect of increasing age and percentage of female patients were performed using meta-regression analysis. Data were also examined for potential publication bias using the Egger and Begg tests as well as funnel plots where RDs were plotted against their corresponding standard errors [13,14]. All statistical tests were 2 -sided tests with $\mathrm{p}<0.05$ regarded as statistically significant. Analyses were done using SAS ${ }^{\circledR}$ (Cary, NC) Version 9.1 and Comprehensive Meta-Analysis Version 2. 


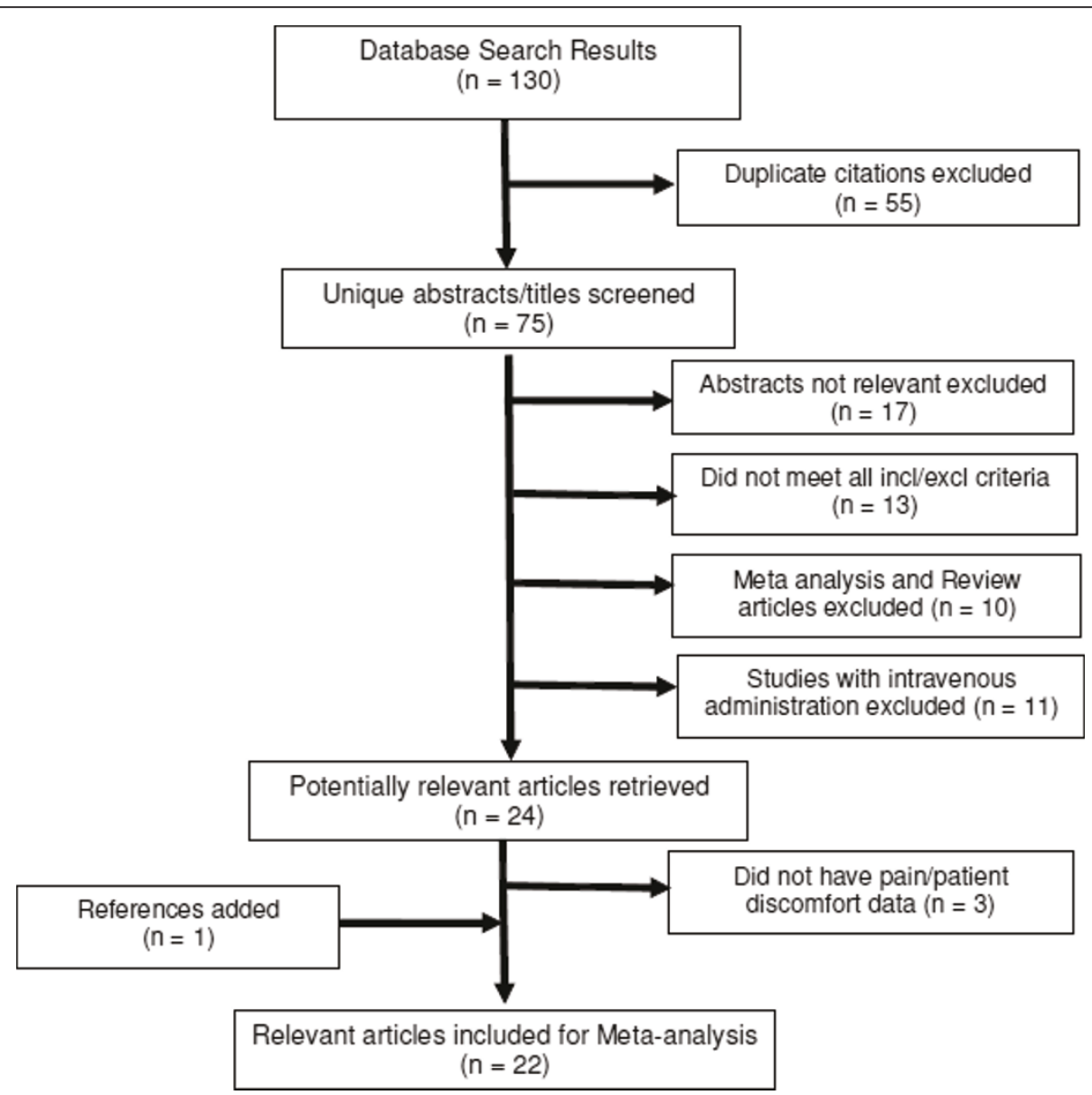

Figure 1 Flow chart outlining literature search and study selection strategy.

\section{Results}

Following the elimination of duplicates from the search results, a total of 75 abstracts were reviewed with 21 articles meeting the predetermined inclusion criteria and one study being added from prior knowledge of the literature as shown in Figure 1. Fifty-one abstracts excluded for the following reasons: 17 studies were preclinical, involved skin testing, hemodynamic assessment, oral hydration, comparative technologies, or had no patient reported outcomes; 13 studies did not use IOCM (iodixanol), were not head-to-head IOCM (iodixanol) versus LOCM, or were not blinded; 11 studies used IV administration; and 10 were meta-analysis and review articles. No attempts were made to contact study authors to either confirm the published trial results or include any unpublished trial results.

The study quality was generally excellent for the RCTs included, with a Jadad score $\geq 2$. Most of the articles included a discussion of pain, discomfort or warmth. Some studies were included more than once in the meta-analysis according to the parameter reported, thus the numbers of articles discussed when totaled summed to more than 22 in some instances.

\section{Characteristics of Reviewed Studies}

Table 1 shows an overview of the studies included [15-36]. The patient population sizes for all the reviewed trials, with the exception of three large studies, ranged from 19 to 165 per treatment group; the number enrolled in each of the large studies was greater than 1000 [15-17]. The average age among the 22 trials $(\mathrm{n}=8087)$ was similar between the two groups, 62.5 years for IOCM (iodixanol) and 61.7 years for all LOCMs combined. The proportions of female patients in the IOCM (iodixanol) and LOCM groups were similar (29\% and $30.5 \%$, respectively). Although the average body weight, when compared for the individual IOCM (iodixanol) versus LOCM trials appeared to be similar, patients in the pooled IOCM (iodixanol) arms had significantly lower body weight than those in all LOCM groups combined $(74.5 \mathrm{~kg}$ vs. $80.2 \mathrm{~kg}$, respectively). The individual LOCMs compared in the trials included iohexol, ioxaglate, iopamidol, and iomeprol. 
Table 1 Study characteristics of RCTs included in the meta-analysis

\begin{tabular}{|c|c|c|c|c|c|c|}
\hline Study & Injection Site and/or Procedure & $\begin{array}{l}\text { Treatment } \\
\text { group }\end{array}$ & $\begin{array}{l}\text { Number of patients } \\
\text { in comfort analysis }\end{array}$ & $\begin{array}{l}\text { Number (\%) } \\
\text { of Females }\end{array}$ & $\begin{array}{c}\text { Age } \\
\text { (Mean } \\
\text { [SD]) }\end{array}$ & $\begin{array}{c}\text { Weight } \\
\text { (Mean } \\
\text { [SD]) }\end{array}$ \\
\hline \multirow[t]{2}{*}{ Andersen et al[28] } & $\begin{array}{l}\text { Left ventricle \& selective coronary artery } \\
\text { injections (left and right) }\end{array}$ & lodixanol & 36 & $9(25.0)$ & 54 & 81 \\
\hline & & loxaglate & 38 & $13(34.2)$ & 56 & 77 \\
\hline \multirow[t]{2}{*}{ Fischbach et al[29] } & Celiac trunk/spiral CT angiography & lodixanol & 40 & $10(25.0)$ & $65.7 \pm 11.4$ & $77.1 \pm 14.7$ \\
\hline & & loversol & 38 & $6(15.8)$ & $61 \pm 11.1$ & $78 \pm 11.5$ \\
\hline \multirow[t]{2}{*}{ Flinck et al[30] } & Cardioangiography & lodixanol & 44 & $8(18.2)$ & 62.5 & 80 \\
\hline & & loxaglate & 44 & $8(18.2)$ & 62.5 & 80 \\
\hline \multirow[t]{2}{*}{ Hekster et al[31] } & $\begin{array}{l}\text { Multiple carotid and vertebral } \\
\text { arteries/IA cerebral DSA }\end{array}$ & lodixanol & 40 & $16(40.0)$ & 61 & 74 \\
\hline & & lohexol & 39 & $14(35.9)$ & 57 & 71 \\
\hline \multirow[t]{2}{*}{ Hill et al[32] } & Coronary and left ventricular angiography & lodixanol & 101 & $20(19.8)$ & $61 \pm 10.0$ & unknown \\
\hline & & lohexol & 99 & $12(12.1)$ & $59 \pm 11.0$ & unknown \\
\hline \multirow[t]{2}{*}{ Justesen et al[15] } & Femoral arteriography & lodixanol & 1225 & $343(28.0)$ & $65.6 \pm 11.5$ & $71.8 \pm 12.5$ \\
\hline & & lopromide & 1227 & $339(27.6)$ & $65 \pm 11.3$ & $71.7 \pm 12.9$ \\
\hline \multirow[t]{2}{*}{ Kendall et al[24] } & IA cerebral digital subtraction angiography & lodixanol & 44 & $22(50.0)$ & $49.7 \pm 11.0$ & $70.2 \pm 13.5$ \\
\hline & & lohexol & 42 & $24(57.1)$ & $45.7 \pm 13.3$ & $70.9 \pm 13.4$ \\
\hline \multirow[t]{2}{*}{ Klow et al[33] } & $\begin{array}{l}\text { Left ventriculography, selective coronary } \\
\text { arteriography, and thoracic aortography }\end{array}$ & lodixanol & 35 & unknown & $54 \pm 9.0$ & $80 \pm 10.0$ \\
\hline & & lohexol & 37 & unknown & $55 \pm 9.0$ & $81 \pm 13.0$ \\
\hline \multirow[t]{2}{*}{ Manke et al[22] } & Femoral arteriography & lodixanol & 163 & $22(13.5)$ & $63.6 \pm 11.2$ & $74.4 \pm 12.9$ \\
\hline & & lomeprol & 165 & $36(21.8)$ & $65.2 \pm 11.6$ & $74.8 \pm 12.6$ \\
\hline \multirow[t]{2}{*}{ Manninen et al[34] } & IA & lodixanol & 50 & $24(48.0)$ & 69 & unknown \\
\hline & & lohexol & 50 & $24(48.0)$ & 69 & unknown \\
\hline \multirow[t]{2}{*}{ Palmers et al[25] } & Cerebral arteriography & lodixanol & 40 & $14(35.0)$ & 54.9 & 69.7 \\
\hline & & loxaglate & 40 & $18(45.0)$ & 48.9 & 73.9 \\
\hline \multirow[t]{2}{*}{ Poirier et al [18] } & Cerebral angiography & lodixanol & 51 & unknown & unknown & unknown \\
\hline & & lohexol & 48 & unknown & unknown & unknown \\
\hline \multirow[t]{2}{*}{ Pugh et al [19] } & Femoral arteriography & lodixanol & 48 & $12(25.0)$ & $65 \pm 8.9$ & $74.3 \pm 14.7$ \\
\hline & & lopromide & 47 & $13(27.7)$ & $68 \pm 10.4$ & $73.9 \pm 12.1$ \\
\hline \multirow[t]{2}{*}{ Roriz et al [26] } & Left ventricular cardioangiography & lodixanol & 54 & $13(24.1)$ & $58 \pm 11.0$ & $75 \pm 9.0$ \\
\hline & & loxaglate & 53 & $13(24.5)$ & $57 \pm 10.0$ & $75 \pm 12.0$ \\
\hline \multirow[t]{2}{*}{ Rosenblum et al [27] } & Peripheral and aortic angiography & lodixanol & 19 & $13(68.4)$ & $64 \pm 11.0$ & $76 \pm 18.0$ \\
\hline & & loxaglate & 25 & $9(36.0)$ & $68 \pm 9.0$ & $76 \pm 16.0$ \\
\hline \multirow[t]{2}{*}{ Siegel et al [21] } & Aortography, renal/visceral angiography & lodixanol & 29 & $11(37.9)$ & $51 \pm 19.0$ & $76 \pm 17.0$ \\
\hline & & loxaglate & 25 & $9(36.0)$ & $52 \pm 15.0$ & $74 \pm 18.0$ \\
\hline \multirow[t]{2}{*}{ Singh et al [35] } & Abdominal aorta/Abdominal angiography & lodixanol & 39 & $10(25.6)$ & 59.1 & 70.3 \\
\hline & & lohexol & 20 & $8(40.0)$ & 66.1 & 70.3 \\
\hline \multirow[t]{2}{*}{ Sutton et al [16] } & $\begin{array}{c}\text { Cardiac catheterization/femoral } \\
\text { arteriography }\end{array}$ & lodixanol & 468 & $173(37.0)$ & $60.2 \pm 10.0$ & $76.5 \pm 14.7$ \\
\hline & & $\begin{array}{l}\text { loxaglate, } \\
\text { lopamidol }\end{array}$ & 1128 & $367(32.5)$ & 60.3 & 95.1 \\
\hline \multirow[t]{2}{*}{ Sutton et al [17] } & $\begin{array}{c}\text { Cardiac catheterization/coronary } \\
\text { angiography }\end{array}$ & lodixanol & 665 & $222(33.4)$ & $60.7 \pm 10.2$ & $78 \pm 14.0$ \\
\hline & & $\begin{array}{l}\text { lopamidol, } \\
\text { lomeprol }\end{array}$ & 1443 & $505(35.0)$ & 60.4 & 78.5 \\
\hline \multirow[t]{2}{*}{ Thorstensen et al [23] } & Femoral arteriography & lodixanol & 73 & $31(42.5)$ & $67.6 \pm 12.5$ & $68 \pm 12.9$ \\
\hline & & lohexol & 74 & $33(44.6)$ & $67.8 \pm 11.3$ & $70.2 \pm 14.5$ \\
\hline
\end{tabular}


Table 1 Study characteristics of RCTs included in the meta-analysis (Continued)

\begin{tabular}{|c|c|c|c|c|c|c|}
\hline \multirow[t]{2}{*}{ Tveit et al [36] } & \multirow[t]{2}{*}{ Left ventricular cardioangiography } & lodixanol & 53 & $9(17.0)$ & 58 & 76.9 \\
\hline & & loxaglate & 49 & $12(24.5)$ & 58 & 77.9 \\
\hline \multirow[t]{2}{*}{ Verow et al [20] } & \multirow[t]{2}{*}{ Aorta/Femoral arteriography } & lodixanol & 68 & unknown & unknown & unknown \\
\hline & & lopamidol & 65 & unknown & unknown & unknown \\
\hline \multirow[t]{2}{*}{ Combined papers } & & lodixanol & 3385 & $982(29)$ & 62.5 & $74.5^{*}$ \\
\hline & & $\begin{array}{l}\text { All LOCMs } \\
\text { Combined }\end{array}$ & 4796 & $1463(30.5)$ & 61.7 & 80.2 \\
\hline
\end{tabular}

*Indicates significant difference between groups $(p<0.05)$.

\section{Contrast Media Associated Patient Discomfort}

Thirteen of the 22 trials included data on patient discomfort associated with intra-arterial injections $(n=3567)$ and most of these data did not report severity of discomfort (Figure 2A). In the 2 studies that reported severity, more than $50 \%$ of the patient population classified the sensation as mild $[18,19]$. There was a significant, though small, difference observed in patient discomfort regardless of severity between IOCM (iodixanol) and all LOCMs (the overall RD was -0.049 (95\% confidence interval $[\mathrm{CI}]:-0.076,-0.021 ; \mathrm{p}=0.001)$ in favor of IOCM (iodixanol). Heterogeneity across studies was observed (Cochran's $\mathrm{Q}=21.247 ; \mathrm{p}=0.047 ; \mathrm{I}^{2}=43.5$ ) (Figure 2B). IOCM (iodixanol) was the favored CM both when the trial data were analyzed individually against each LOCM (ioxaglate, iohexol, iopromide) for discomfort regardless of severity and for all LOCMs combined as a group. The number of studies identified for iopamidol $(n=1)$ and iomeprol $(\mathrm{n}=0)$ was not adequate to allow the meta-analysis for incidence of discomfort to be performed for these LOCMs. However, the IOCM iodixanol was favored when compared to iopamidol $(p=0.028)$ [20].

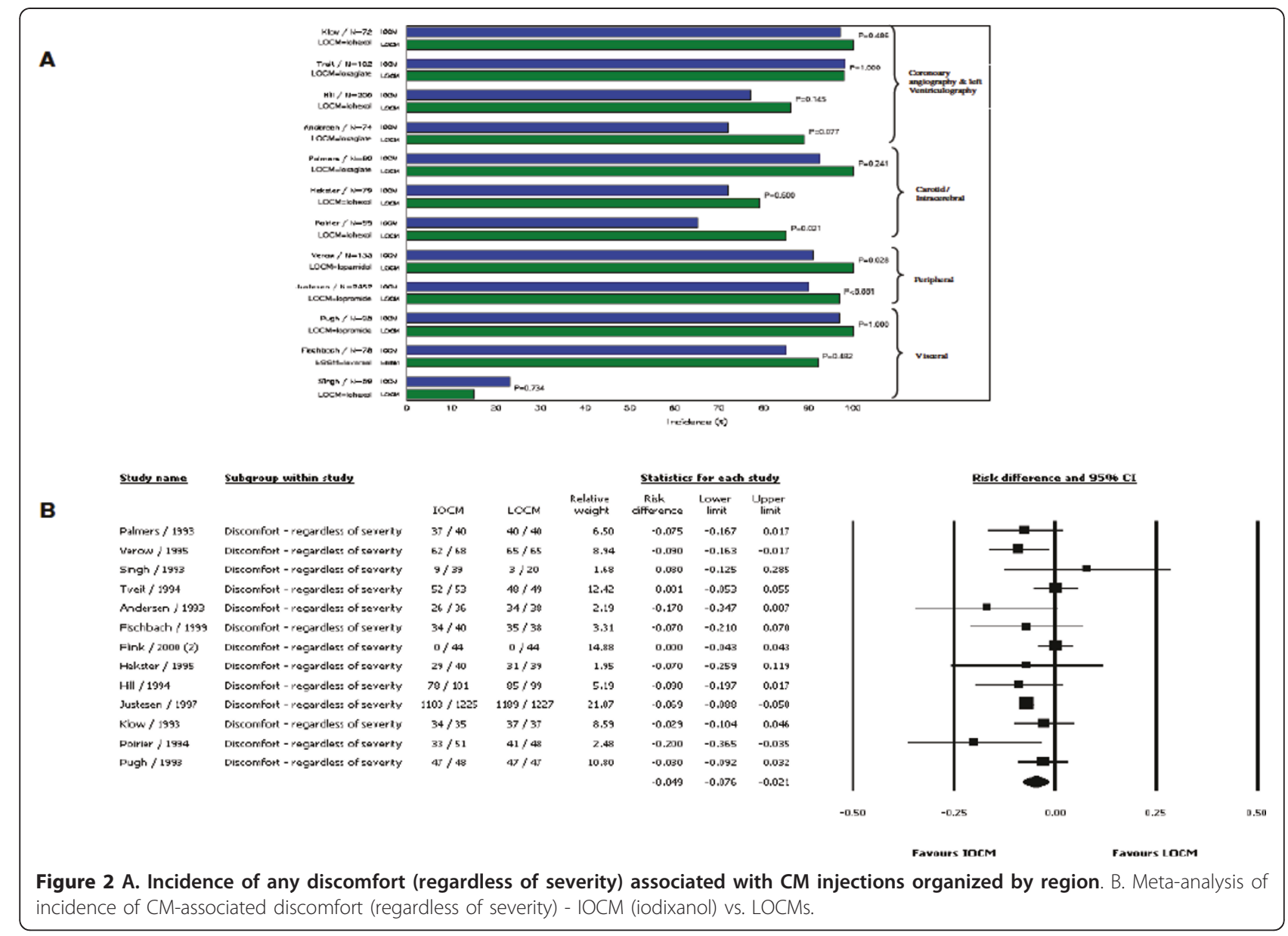




\section{Patient Reported Pain}

Figure 3 presents the incidence of $\mathrm{CM}$-associated pain based on severity in three panels: Panel A illustrates the incidence data on pain, based on severity, reported by a total of 7 trials $(\mathrm{n}=881)$; Panel B illustrates the assessment of any pain associated with CM injections in 10 trials ( $n=3482$ ); and Panel $C$ illustrates results from the meta-analysis. Contrary to the observations in patient discomfort studies discussed above, a more pronounced difference was evident in the incidence of pain between IOCM (iodixanol) and LOCM in seven RCTs. The difference in the magnitude of patient-reported pain between IOCM (iodixanol) versus LOCMs (ioxaglate, iohexol, and iopamidol) was greater for peripheral and carotid/intracerebral procedures compared to visceral procedures. Although 3 of the 10 studies included in the analysis reported no statistically significant difference in the incidence of pain (Poirier et al, $\mathrm{p}=0.062$; Pugh et al, $\mathrm{p}=1.000$; Siegel et al, $\mathrm{p}=0.093$ ) between iodixanol vs. iopromide, iohexol, and ioxaglate, respectively (Figure 3B), our meta-analysis favored IOCM (iodixanol) compared to all LOCMs combined, with a summary RD value of -0.188 (95\% CI: $-0.265,-0.112$; $\mathrm{p}<0.001)$ for incidence of pain, regardless of the severity $[18,19,21]$. The overall effect size was $-0.191,95 \%$ CI: -0.305 , -0.077; $\mathrm{p}<0.001$ when patient-reported incidence of pain was based on moderate or severe vs. none or mild intensity. IOCM (iodixanol) was the favored CM both when the trial data were analyzed individually against each LOCM for which at least three studies were available (ioxaglate and iohexol) and for all LOCMs combined as a group. The number of studies identified for iopamidol $(n=1)$ and iomeprol $(n=1)$ was not adequate to allow the meta-analysis for incidence of pain to be performed for these LOCMs. However, the IOCM iodixanol was favored when compared to iopamidol ( $\mathrm{p}<$ $0.001)$ and to iomeprol $(\mathrm{p}=0.007)[20,22]$.

\section{Warmth Sensation}

Of the 22 RCTs, 15 (68\%; $n=5899)$ reported the incidence of warmth with injection, and 13 studies (59\%; $\mathrm{n}$ = 7302) provided information on its severity. Injectionrelated warmth was reported by more than $90 \%$ of patients, irrespective of the CM used. With the exception of three trials, there were no statistically significant differences between IOCM (iodixanol) and LOCMs (ioxaglate, iohexol, iomeprol, iopromide, iopamidol) regarding the incidence of warmth $[15,18,23]$. One of the two studies that did not report severity data showed a significant difference between iodixanol (57\%) and iohexol (77\%), $\mathrm{p}=0.036$ [18]. The meta-analysis of the warmth data modestly favored IOCM (iodixanol) over LOCMs (Figure 4, upper panel) with an effect size of -0.043 (95\% CI: $-0.074,-0.011 ; \mathrm{p}=0.008$ ). This effect was more pronounced when the incidence of warmth was evaluated by severity (Figure 4, lower panel). The RD for the latter was -0.201 (95\% CI: $-0.270,-0.131$; p < 0.001). Similarly, when the meta-analysis for incidence of warmth (with or without the severity data) was performed against each LOCM, iodixanol was favored over ioxaglate, iopromide, and iohexol. The three studies comparing iodixanol vs. iopamidol did not favor either agent. No evidence of publication bias was noted among the studies reporting CM-associated warmth.

\section{Cold Sensation}

Only five studies reported data $(n=450)$ on CMassociated cold sensation experienced by patients undergoing radiological procedures [20,24-27]. Minimal rates ( $<5.3 \%)$ of mild coldness were reported by patients given IOCM iodixanol. The meta-analysis of CM-associated cold sensation (with or without severity) did not show a difference between IOCM (iodixanol) and LOCM with an overall effect size of 0.008 (95\% CI: $-0.013,0.030 ; \mathrm{p}=0.0449)$ using a fixed or random effects model.

\section{Multivariate Meta-regression Analysis}

The results of the meta-regression analyses with RD of each event as the dependent variable and increasing age and proportion of women as the independent variables are presented in Figure 5. With regard to incidence of pain (moderate or severe vs. none or mild), there was a slight increase of RDs with increasing age (Tau-squared $=0.01467$, slope $=0.00690$ and intercept $=-0.5137$ ) (Figure 5, Panel A), whereas the RD tended to decline with and increasing percent of women enrolled in the trials (Tau-squared $=0.0111$, slope $=-0.00663$ and intercept $=0.10932)($ Figure 5, Panel B). The opposite age and gender trends were found with warmth sensation as the outcome (Figure 5, Panels C and D) with Tausquared values of 0.00768 and 0.0078 , respectively.

\section{Discussion}

We found that the intra-arterial use of IOCM (iodixanol) compared with individual LOCM agents or LOCM as a group was associated with reduced frequency and severity of pain, warmth, and discomfort reported by patients in prospective, head-to-head, RCTs. Older age was associated with greater effect sizes with respect to pain but lesser effects with warmth. The opposite trends were noted as the proportion of women increased in the trials, suggesting both age and gender modify patientreported outcomes according to the osmolality of CM. There was a moderate degree of heterogeneity among the trials because of differences in trial design, reporting methods of patient symptoms, and external consistency between the trials. There was no evidence of publication 


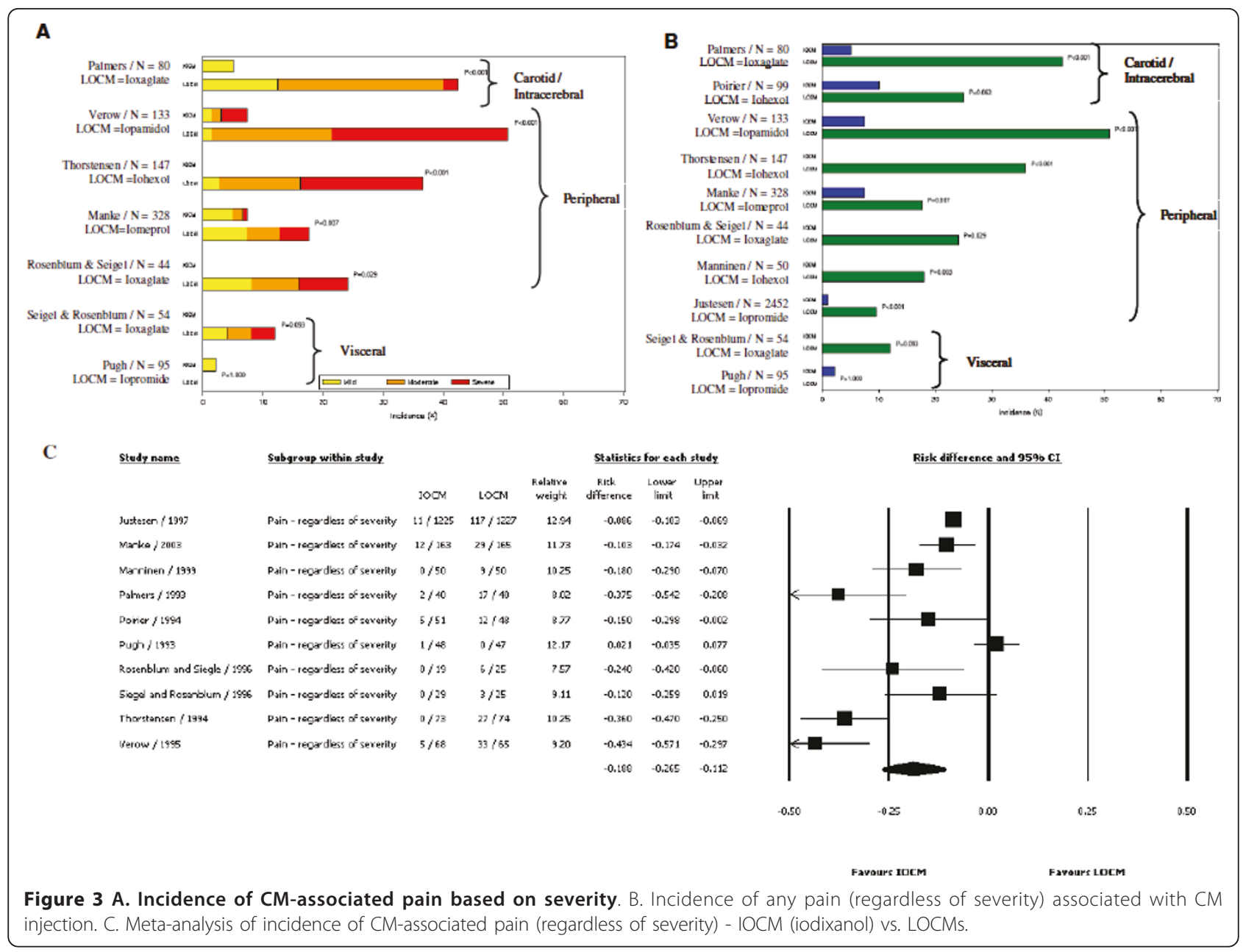

bias, and we do not expect additional trials to overturn the results of this analysis.

Our data are consistent with what is known about the vascular biologic effects of iodinated CM. All forms of iodinated $\mathrm{CM}$ position iodine on a single benzene ring or a dimer of such rings. The presence or absence of charged side chains, particle concentration in solution (osmolality), viscosity, and iodine concentrations are the main physiochemical characteristics that make each formulation unique. Iodixanol is an iso-osmolar, nonionic, dimer that is isotonic with blood. It is believed that this formulation results in less deformation of cell membranes in blood and the vascular endothelium. As a result, there is an attenuated immediate release of histamine from basophils and nitric oxide from vascular endothelial cells. Thus, there is a blunted initial wave of vasodilation throughout the body as $\mathrm{CM}$ travels through the vasculature. In addition, with iso-osmolality, a less pronounced vasoconstriction is anticipated following the initial phase of endothelium-dependent vasodilation. As a result, there is greater vascular stability in arterioles that serve the skeletal muscles and skin in the extremities. This attenuates the activation of nociceptors in nerves supplying both the neurovascular bundles as well as the end-organs. Because the greatest physiochemical difference between IOCM (iodixanol) and LOCM is osmolality as opposed to iodine content or viscosity, we believe, our data support osmolality being the main determinant of symptoms after intravascular injection.

The clinical importance of our findings is highlighted in the ever increasing use of iodinated contrast for intravascular imaging procedures. Our results extend the observations of Justesen and coworkers whose trial included in our meta-analysis [15]. In this trial alone, 1225 patients were randomized to iodixanol and 1227 to iopromide in conventional/digital subtraction angiography of the femoral arterial system. The iodixanol group reported statistically significantly less injection-associated pain $(0.9 \%)$ than the iopromide group $(9.5 \%)$ ( $\mathrm{p}<$ 0.001 ). In addition, $4.1 \%$ in the iodixanol group experienced pain and/or severe heat sensation vs $19.8 \%$ in the iopromide group $(\mathrm{p}<0.001)$. Our analysis suggests these 


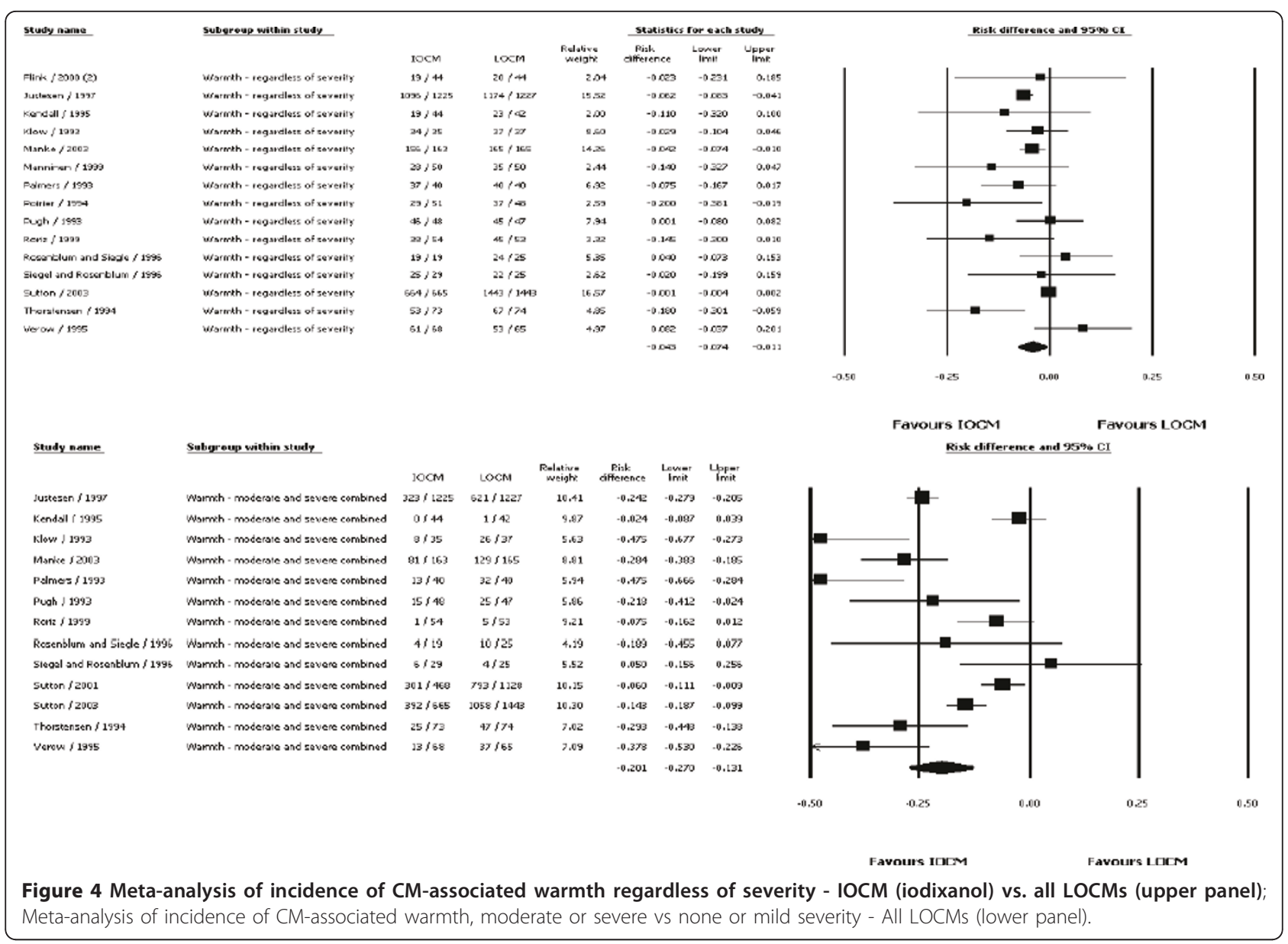

findings can be generalized to other peripheral arterial beds and left ventriculography.

Reduction in pain and discomfort is an important goal for improving the overall tolerability of any procedure. If symptoms related to CM cause tachycardia or body motion, the procedure may be prolonged and the quality of a variety of imaging tests could be affected. This threatens the diagnostic accuracy and subsequent clinical decision making. In addition, poor image quality because of motion artifact may influence the outcomes of an interventional procedure such as a vascular stent placement planned from digital subtraction angiography. Moreover, non-diagnostic studies often lead to repeated examinations, exposing patients to additional injections of contrast and higher doses of radiation. Thus, for all of these reasons, the choice of IOCM over LOCM would be supported in peripheral arteriography procedures where higher degrees of discomfort or body motion would be expected with injection.

Our analysis has all the limitations of any tabular metaanalysis: the response variables measured, stratifications reported, and the individual trial sample sizes. We did not have information on the rates of injection, bolus size, or the use of power injectors, or the use of conscious sedation and analgesic medications which could have influenced the overall size and concentration of CM moving en bloc through the vasculature and its triggering of nociceptors. Importantly, none of the studies had physiologic correlates such as skin temperature, bioimpedance, or plethysmography to investigate the neurovascular origins of discomfort reported. We had insufficient information on the injection site to draw conclusions on outcomes in typically very sensitive vascular territories (distal upper limb and pudendal artery) as well as on injection rates and CM concentration. We included coronary angiography, which for the most part elicits few symptoms, and thus, biased our findings to the null hypothesis. This being considered, the large effect size, internal and external consistency, and absence of publication bias all suggest the differential findings among the CM are valid and likely to be reproduced in everyday clinical practice. Finally, we did not have data on patient motion and image quality, but we suspect in cases where the discomfort was greater, there was more patient motion and the possibility of reduction in image quality. 


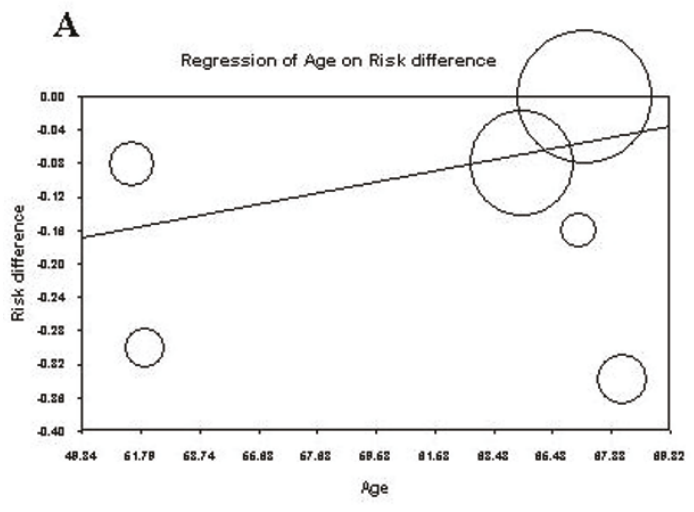

C

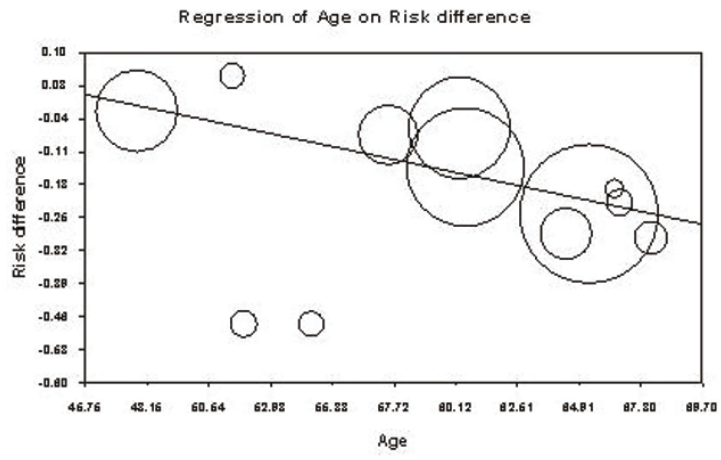

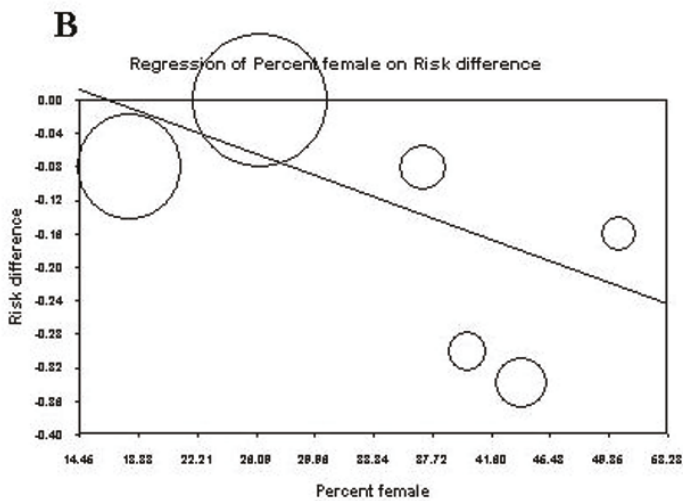

D

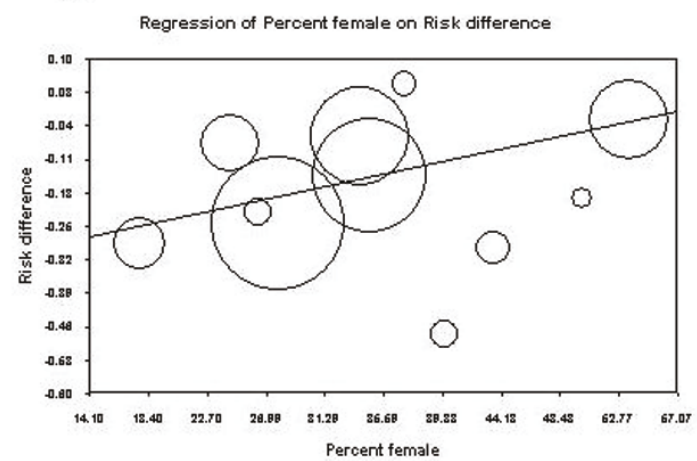

Figure 5 Bivariate fixed-effects meta-regression analysis with continuous covariates. The open circles in each panel represent the primary trials. The area of each circle is directly proportional to the relative weight of that study. The solid line is the regression line. (Panels A and B represent the incidence of CM-associated pain with severity; Panels C and D represent CM-associated warmth with severity).

\section{Conclusions}

In conclusion, IOCM (iodixanol) is associated with less frequent and severe patient discomfort characterized as pain and warmth during intravascular administration compared to the individual LOCM or LOCM as a group. These data support difference in osmolality as the major determinant of such symptoms with CM use.

\section{Acknowledgements}

The authors would like to thank Adrienne H. Groulx (M.Sc., Senior Biostatistician, i3 Statprobe employee) for assisting with data extraction and statistical analyses and Sujatha Sundaram (Ph.D., i3 Statprobe consultant) for assisting with preparation of the manuscript.

\section{Author details}

${ }^{1}$ St. John Providence Health System, Department of Medicine, Cardiology Section, Providence Park Heart Institute, Novi, MI, USA. ${ }^{2}$ Department of Radiology, Division of Vascular \& Interventional Radiology University of Kentucky, Lexington, KY, USA.

\section{Authors' contributions}

PM directed the study design, literature search, reviewed the findings, directed the coding and scoring of papers, tabular synthesis, meta-analysis, and meta-regression. PM drafted the original manuscript and provided edits and clarifications. PC provided input on the concept of the paper, scope of the clinical applications to be studied, review of the tabular and metaanalytic results, and edits and reviews of manuscript versions. Both authors had full access to the raw data set and take responsibility for the integrity of the data and the accuracy of the analysis, results, and discussion. Both authors read and approved the final manuscript.

\section{Competing interests}

This meta-analysis was supported by GE Healthcare, Inc. Medical Diagnostics, Princeton, NJ, USA. GE Healthcare directly contracted with Nerac Inc., Toland, $C T$, USA, for access and maintenance of the library of papers and abstracts used in the study. GE Healthcare also directly contracted with i3 Statprobe, Inc., Ann Arbor, MI USA for the services listed above. Drs. McCullough and Capasso have served as consultants to GE Healthcare in the past.

Received: 29 January 2011 Accepted: 24 May 2011

Published: 24 May 2011

\section{References}

1. McCullough PA: Renal safety of iodixanol. Expert Rev Cardiovasc Ther 2006, 4:655-661

2. Wolf $G L$ : Adult peripheral angiography. Results from four North American randomized clinical trials of ionic media vs. iohexol. Invest Radiol 1985, 20:S108-S111.

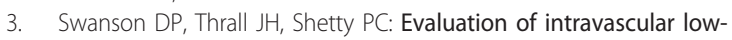
osmolality contrast agents. Clin Pharm 1986, 5:877-891.

4. Dawson P: The non-ionic isotonic contrast agents. Perspectives and controversies. Eur Radiol 1996, 6(Suppl 2):S20-S24.

5. Kushner FG, Hand M, Smith SC Jr, et al: 2009 focused updates: ACC/AHA guidelines for the management of patients with ST-elevation myocardial infarction (updating the 2004 guideline and 2007 focused update) and ACC/AHA/SCAl guidelines on percutaneous coronary intervention (updating the 2005 guideline and 2007 focused update) a report of the American College of Cardiology Foundation/American Heart Association Task Force on Practice Guidelines. J Am Coll Cardiol 2009, 54:2205-2241. 
6. Solomon R: The role of osmolality in the incidence of contrast-induced nephropathy: a systematic review of angiographic contrast media in high risk patients. Kidney Int 2005, 68:2256-2263.

7. Solomon R, Dumouchel W: Contrast media and nephropathy: findings from systematic analysis and Food and Drug Administration reports of adverse effects. Invest Radiol 2006, 41:651-660.

8. Thomsen HS: Current evidence on prevention and management of contrast-induced nephropathy. Eur Radiol 2007, 17(Suppl 6):F33-F37.

9. Weisbord SD, Palevsky PM: Radiocontrast-induced acute renal failure. $J$ Intensive Care Med 2005, 20:63-75.

10. Mathers SA, Chesson RA, Proctor JM, McKenzie GA, Robertson E: The use of patient-centered outcome measures in radiology: a systematic review. Acad Radiol 2006, 13:1394-1404.

11. Jadad AR, Moore RA, Carroll D, et al: Assessing the quality of reports of randomized clinical trials: is blinding necessary? Control Clin Trials 1996, 17:1-12.

12. DerSimonian R, Laird N: Meta-Analysis in Clinical Trials. Controlled Clinical Trials 2009, 7:177-188.

13. Egger M, Davey SG, Schneider M, Minder C: Bias in meta-analysis detected by a simple, graphical test. $B M J$ 1997, 315:629-634.

14. Begg $C B$, Mazumdar $M$ : Operating characteristics of a rank correlation test for publication bias. Biometrics 1994, 50:1088-1101.

15. Justesen P, Downes M, Grynne BH, Lang H, Rasch W, Seim E: Injectionassociated pain in femoral arteriography: a European multicenter study comparing safety, tolerability, and efficacy of iodixanol and iopromide. Cardiovasc Intervent Radiol 1997, 20:251-256.

16. Sutton $A G$, Finn $P$, Grech $E D$, et al: Early and late reactions after the use of iopamidol 340 , ioxaglate 320 , and iodixanol 320 in cardiac catheterization. Am Heart J 2001, 141:677-683.

17. Sutton $A G$, Finn $P$, Campbell $P G$, et al: Early and late reactions following the use of iopamidol 340, iomeprol 350 and iodixanol 320 in cardiac catheterization. J Invasive Cardiol 2003, 15:133-138.

18. Poirier VC, Monsein LH, Newberry PD, Kreps BJ: Double-blind, randomized comparison of iodixanol 320 and iohexol 300 for cerebral angiography. Invest Radiol 1994, 29(Suppl 2):S43-S44.

19. Pugh ND, Sissons GR, Ruttley MS, Berg KJ, Nossen JO, Eide H: lodixanol in femoral arteriography (phase III): a comparative double-blind parallel trial between iodixanol and iopromide. Clin Radiol 1993, 47:96-99.

20. Verow P, Nossen JO, Sheppick A, Kjaersgaard P: A comparison of iodixanol with iopamidol in aorto-femoral angiography. Br J Radiol 1995, 68:973-978.

21. Siegel EL, Rosenblum JD, Eckard DA, et al: Comparison of iodixanol and ioxaglate for adult aortography and renal/visceral angiography: a phase III clinical trial. Acad Radiol 1996, 3(Suppl 3):S507-S513.

22. Manke C, Marcus C, Page A, Puey J, Batakis O, Fog A: Pain in femoral arteriography. A double-blind, randomized, clinical study comparing safety and efficacy of the iso-osmolar iodixanol $270 \mathrm{mgl} / \mathrm{ml}$ and the low-osmolar iomeprol $300 \mathrm{mgl} / \mathrm{ml}$ in 9 European centers. Acta Radiol 2003, 44:590-596.

23. Thorstensen $\mathrm{O}$, Albrechtsson $U$, Calissendorff $B$, et al: lodixanol in femoral arteriography. A randomized, double-blind, phase III, parallel study with iodixanol $270 \mathrm{mg} \mathrm{l} / \mathrm{ml}$ and iohexol $300 \mathrm{mg} \mathrm{I} / \mathrm{ml}$. Acta Radiol 1994, 35:629-631.

24. Kendall BE, Sheppick A, Nossen JO, Stevens JM: lodixanol in intra-arterial cerebral digital subtraction angiography: a comparison with iohexol. Neuroradiology 1995, 37:512-514.

25. Palmers Y, De GD, Grynne BH, Smits J, Put E: A double-blind study comparing safety, tolerability and efficacy of iodixanol $320 \mathrm{mgl} / \mathrm{ml}$ and ioxaglate $320 \mathrm{mgl} / \mathrm{ml}$ in cerebral arteriography. Eur J Radiol 1993, 17:203-209.

26. Roriz R, de GG, Finet G, et al: Comparison of iodixanol (Visipaque) and ioxaglate (Hexabrix) in coronary angiography and ventriculography: a double-blind randomized study. J Radiol 1999, 80:727-732.

27. Rosenblum JD, Siegel EL, Leef J, Eckard DA, Lu CT: lodixanol and ioxaglate in adult aortography and peripheral arteriography: a phase III clinical trial. Acad Radiol 1996, 3(Suppl 3):S514-S518.

28. Andersen PE, Bolstad B, Berg KJ, Justesen P, Thayssen P, Kloster YF: lodixanol and ioxaglate in cardioangiography: a double-blind randomized phase III study. Clin Radiol 1993, 48:268-272.
29. Fischbach $R$, Landwehr $P$, Svaland $M$, et al: Spiral $C T$ angiography of the abdominal aorta. Comparison of iodixanol and ioversol. Invest Radiol 1999, 34:374-380.

30. Flinck A, Selin K: Vectorcardiographic changes during cardioangiography with iodixanol and ioxaglate. Int J Cardiol 2000, 76:173-180.

31. Hekster RE, Morre HH, Cleyndert P, et al: Intra-arterial digital subtraction angiography with isotonic dimeric (iodixanol) and monomeric (iohexol) nonionic contrast media: radiographic, clinical and neurophysiological evaluation. Neuroradiology 1995, 37:48-50

32. Hill JA, Cohen MB, Kou WH, et al: lodixanol, a new isosmotic nonionic contrast agent compared with iohexol in cardiac angiography. Am J Cardiol 1994, 74:57-63.

33. Klow NE, Levorstad K, Berg KJ, et al: lodixanol in cardioangiography in patients with coronary artery disease. Tolerability, cardiac and renal effects. Acta Radiol 1993, 34:72-77.

34. Manninen HI, Yang XM, Soder H, Matsi PJ, Borch KW, Eide H: Comparison of iodixanol 270 with iohexol 300 in infrapopliteal arteriography. Digital densitometric analysis of angiographic opacification. Acta Radiol 1999, 40:291-295.

35. Singh K, Sundgren R, Bolstad B, Bjork L, Lie M: lodixanol in abdominal digital subtraction angiography. A randomized, double-blind, parallel trial with iodixanol and iohexol. Acta Radiol 1993, 34:242-245.

36. Tveit K, Bolz KD, Bolstad B, et al: lodixanol in cardioangiography. A double-blind parallel comparison between iodixanol $320 \mathrm{mg} \mathrm{I} / \mathrm{ml}$ and ioxaglate $320 \mathrm{mg} \mathrm{l} / \mathrm{ml}$. Acta Radiol 1994, 35:614-618.

\section{Pre-publication history}

The pre-publication history for this paper can be accessed here: http://www.biomedcentral.com/1471-2342/11/12/prepub

doi:10.1186/1471-2342-11-12

Cite this article as: McCullough and Capasso: Patient Discomfort Associated with the Use of Intra-arterial lodinated Contrast Media: A Meta-Analysis of Comparative Randomized Controlled Trials. BMC Medical Imaging 2011 11:12.

\section{Submit your next manuscript to BioMed Central and take full advantage of:}

- Convenient online submission

- Thorough peer review

- No space constraints or color figure charges

- Immediate publication on acceptance

- Inclusion in PubMed, CAS, Scopus and Google Scholar

- Research which is freely available for redistribution

Submit your manuscript at www.biomedcentral.com/submit
C Biomed Central 